This article was published in Medical Engineering and Physics, 37(8), 719-728, 2015 http://dx.doi.org/10.1016/j.medengphy.2015.05.015

\title{
From mechanical stimulus to bone formation: A review
}

\author{
Natacha Rosa a,*, Ricardo Simoes ${ }^{b, c}$, Fernão D. Magalhães ${ }^{d}$, Antonio Torres \\ Marques ${ }^{\mathrm{a}}$ \\ a DEMec, Faculty of Engineering, University of Porto, Rua Roberto Frias, 4200-465 \\ Porto, Portugal \\ b Polytechnic Institute of Cávado and Ave, School of Technology, Campus do \\ IPCA, 4750-810 Barcelos, Portugal \\ c Institute for Polymers and Composites IPC/I3N, University of Minho, Campus \\ de Azurem, 4800-058 Guimarães, Portugal \\ d LEPABE - Faculdade de Engenharia, Universidade do Porto, Rua Roberto Frias, \\ 4200-465 Porto, Portugal
}

\begin{abstract}
Bone is a remarkable tissue that can respond to external stimuli. The importance of mechanical forces on the mass and structural development of bone has long been accepted. This adaptation behaviour is very complex and involves multidisciplinary concepts, and significant progress has recently been made in understanding this process. In this review, we describe the state of the art studies in this area and highlight current insights while simultaneously clarifying some basic yet essential topics related to the origin of mechanical stimulus in bone, the biomechanisms associated with mechanotransduction, the nature of physiological bone stimuli and the test systems most commonly used to study the mechanical stimulation of bone.
\end{abstract}

\section{Introduction}

Understanding the influence of mechanical stimuli on the structure of bone has long been a topic of scientific interest. To the best of our knowledge, Galilei [1], noticed a relationship between body weight and bone size and shape. However, mechanical forces were not identified as responsible for shaping the architecture of the skeleton until the 19th century, in studies developed by Meyer [2], Culmann [3] and Roux [4].

The German anatomist von Meyer identified arched trabecular patterns in a sagittally sectioned human first metatarsal and calcaneus, and Culmann, a pioneer of graphical methods in engineering, suggested that the patterns appeared to be aligned along principal stress directions produced by functional loading [5]. In 1881, Roux proposed that the apposition and absorption of bone is a biological stress-controlled process $[6,7]$.

However, Julius Wolff [8] - influenced by von Meyer-Culmann interactions in 1867 - became associated to the concept of bone adaptation. He claimed that the shape of bone is related to mechanical stress by Wolff's law of bone transformation. Although 
this law is an overly simplified mathematical approach, the concept has been accepted by the scientific community. Recent interpretations of "Wolff's Law" have proposed that bone mass and architecture are to some extent governed by adaptive mechanisms that are sensitive to their mechanical environment [9-11].

Over the years, remarkable work has been done to elucidate bone mechanotransduction and its response to mechanical stimulation. The first contact with this subject can be overwhelming due to the complexity and multidisciplinary mechanisms involved. This review paper aims to establish the state of the art of this area while simultaneously clarifying some basic yet important questions on which light has been shed during recent years, such as

- What is the origin of the mechanical stimulus? How is it triggered?

- How does bones mechanotransduction work?

- What are the normal physiological bone stimuli?

- What test systems are commonly used to study bone's mechanical stimulation?

\section{Mechanical stimulus}

Bone mass is maintained by and adapted to mechanical strain, primarily as the result of muscular contraction [12,13]. Some key aspects are currently accepted by the scientific community at large and should be mentioned.

First, long bones deformation is obtained by an orchestrated muscle activity as demonstrated by Duda et al. [14]. Using a finite element strain distributions model, these authors concluded that simplified load regimes produced differences in strain as high as $26 \%$ compared with regiments that included all thigh muscles. Although this study focused only on the proximal femur situation, this concept can be generalized to other bones in the human body.

Second, the forces experienced by bone arise from muscle action rather than from mere gravitational forces [15]. Hence, muscle mass/strength correlates with bone strength [12]. This concept was demonstrated in a study by Sievänen et al. [16]. The patella bone mineral apparent density and average strain magnitude were measured in a chained event experiment that included one-year unilateral strength training interventions, an accidental knee ligament rupture and a two-year rehabilitation period. The patella was selected as the target bone because it is a nonweight-bearing bone that receives mechanical stimuli from only the quadriceps activity. Sievänen et al. showed that a decline in muscle mass precedes a decline in bone strength under conditions of disuse and that the recovery of muscle mass increases before bone mass. In another study, Schönau etal.[17] compared the muscle development with age as well as muscle development and bone strength.

Disuse can be asserted to cause muscle wasting and bone loss, whereas physical activity increases muscle strength and bone mass. However, according to Rittweger et al. [15], this relationship only holds to a certain extent. The authors claim that muscular exercise can only enhance bone strength up to 1-2\% because tendon stiffness may limit the musculoskeletal peak forces.

In several studies $[9,12,16,18]$, a time lag of up to 5 days was registered between a 
single period of mechanical loading in vivo and the onset of collagen and mineral apposition increases on the bone sur- face. This phenomenon is justified by the delay between the initial formation of new bone and the establishment of fully mineralized and mature bone.

The third key aspect was stated in one of the earliest far-reaching interpretations of bone loading made by Pauwels [19], who suggested that bending moments are transmitted along limbs by a combination of tensile forces in the muscle and compressive forces on bone. Hence, gravitational forces tend to lower and collapse our body segments in any upright posture. However, bending moments are accentuated rather than reduced due to the physiological curvature of long bones. In response to these external loads, muscles not only provide the necessary moment equilibrium in joints, but they counteract the passive bending moments along bones in an energetically efficient manner, as stated by Munih et al. [20]. While reducing the bending stress, muscles increase the axial compressive load irrespective of the posture to ensure minimal bone stress and minimal bone weight [21]. From all registered loading modes in long bone, bending is the most significant for bone adaptation [2224].

Fourth and last, in addition to mechanical stimuli, bone remodelling may also be regulated by hormones, such as estrogen and parathyroid hormone [25,26], and induced by the nervous system [18,27] and inflammatory reactions [28].

\section{Mechanotransduction system}

Over the last several years, osteocytes have become generally accepted as the mechanosensory cells within the bone. Osteocytes coordinate the remodelling process by converting external mechanical forces into biochemical responses - a process known as mechanotransduction. However, the mechanism by which these cells sense the mechanical loads and facilitate adaptive alterations in bone mass and architecture is not yet completely understood $[10,18,29,30]$.

\subsection{Stimuli perceived by osteocytes}

Osteocytes are generally assumed to react to bone deformation or to one of the consequences of bone deformation, such as shear stress due to load-induced fluid flow, electric fields caused by stress- generated streaming potentials, and hydrostatic pressure $[22,31,32]$.

\subsubsection{Cell deformation}

The immediate consequence of mechanical loading is strain, which is a small deformation throughout the calcified matrix. These stimuli will stretch the osteocytes to the same extent as the sur- rounding bone tissue. When stretched in one direction, bone tends to slightly contract in the perpendicular direction. Hence, direct biaxial osteocyte strain is common [9,33]. Several authors [33-35] suggest that the strains experienced by an osteocyte are much higher than those measured on the bone surface, 
with registered amplification factors that are up to 9 times larger than the applied global strain. This difference may be due to a magnification effect caused by the cell's complex surrounding pericellular and extracellular matrix. In a recent study, Wang et al. [36] proposed that the strain amplification factor positively correlates with the loading frequency and loading strain.

\subsection{Shear induced by fluid-flow}

Loading the bone first pressurizes the interstitial fluid around the osteocytes before flow is initiated [32]. A study developed by Gardinier et al. [37] predicted that in vivo osteocytes could experience hydrostatic pressures of up to $5 \mathrm{MPa}$. The interstitial fluid within the lacuno-canalicular (LC) is then driven to flow through the thin layer of nonmineralized pericellular matrix surrounding the osteocytes and towards the Harversian or Volkmann's channels [22,32]. In this sense, bone can be compared to a water-soaked sponge. A compressive force on the sponge will squeeze water out of it. Similarly, mechanical loading will result in a flow of interstitial fluid through the LC network of bone (see Fig. 1) [38]. The flow of interstitial fluid through the LC net- work places shear stress on the cell membranes. This stress is thought to initiate a biochemical response from the cells [39].

Piekarski [40] was the first researcher to propose that mechanical loading induces fluid-flow in bone. He stated that this flow enabled nutrition and waste removal.

The effect of the three-dimensional LC network complex geometry of bone on the fluid flow shear stress stimuli mechanism and its role in osteocyte mechanobiology are not yet fully understood. However, a recent study developed by Verbruggen et al. [41] showed that individual osteocytes may be subjected to a maximum shear stress stimulus of approximately $11 \mathrm{~Pa}$ and an average fluid velocity of $60.5 \mu \mathrm{m} / \mathrm{s}$ in response to vigorous activity. Mechanosensing bone cells also seem to be able to sense low fluid-flow stress values, as demonstrated by Morris et al. [42], Delaine-Smith et al. [43], Young et al. [44].

Several studies have also evaluated the responsiveness of bone cells to different flow profiles. Of these studies, we would like to highlight the important work developed by Jacobs' group [45-47], in which they studied oscillating, pulsatile and steady fluid flow. These studies showed that pre-osteoblast cell lines recognized both steady unidirectional and oscillating fluid flow as an osteogenic stimulus, but the latter was considered to be more realistic in physiologic terms than steady or pulsatile flow. This condition occurs because induced flow through the LC network is reversed when the bone is unloaded [46,47]. Case et al. [46] also claimed that the flow duration and inclusion of rest periods may influence flow effects.

\subsection{Streaming potentials}

In the mid-1960s, researchers observed that mechanical strains generated electrical potential differences along the lateral and longitudinal axes of compact bone. These differences may exert direct effects on bone cells because the in vivo application of an electromagnetic field to bone is known to inhibit bone resorption and stimulate bone formation. Of all of the mechanisms proposed to explain the strain-generated 
potentials, two were selected for analysis: streaming potentials and piezoelectricity $[9,10,48]$.

Streaming potentials are electric fields caused by stress-generated fluid-flow. Initially, streaming potentials were thought to be generated by electrokinetic effects that are associated with the collagen- apatite porosity system of connected micropores. Currently, pores are considered to be the canaliculi in mineralized bone. The bone surface is negatively charged; thus, the interstitial fluid cations that are being forced through channels are attracted to the surface, producing a surplus of ions in the fluid. The voltage that results from this imbalance of ions is positive in the direction of flow. The streaming potential produced by interstitial fluid-flow in bone is believed to be able to produce a number of responses in osteocytes, including the activation of voltageoperated channels in the cellular membrane. Thus, this streaming potential serves to trigger the mechanotransduction process [32,49-51].

\subsubsection{Piezoelectricity}

Yasuda [52] was the first researcher to observe piezoelectric behaviour in bone tissue. Subsequently, Fukada etal. [53] systematically investigated and measured the direct and converse piezoelectric effect in dry specimens cut from human and ox femurs. The centro- symmetric crystal structure of hydroxyapatite excludes the possibility of observing these piezoelectric properties, as demonstrated in decollagenated bone [54]. Minary-Jolandan et al. [55] found that isolated collagen fibrils have unipolar axial polarizations and behave mainly as shear piezoelectric materials with a shear piezoelectric constant of $\mathrm{d} 15 \approx 1 \mathrm{pm} \mathrm{V}^{-1}$ (or $\mathrm{pC} \mathrm{N}^{-1}$ ).

In a recent study, Ahn et al. [10] explored the possible influence of bone piezoelectricity on streaming potentials. The piezoelectricity of collagen may influence the magnitude of the zeta potential and thus the streaming potential. Therefore, it may indirectly modify the stiffness and fluid dynamics of bone. The load may also create a local fixed charge density that may modify the steady state fluid content of the bone and consequently the amount available for transfer from the collagen-hydroxyapatite microporosity to the LC system. This influence in turn affects the fluid-flow around the osteocytes. In a complementary multiscale approach study developed by Lemaire et al. utilized a coupled poro-elastic model of cortical tissue to deter- mine that in vivo electric measurements at the organ scale are due to streaming currents.

Although the precise stimuli bone cells experience in vivo are not yet fully understood, a number of theoretical and experimental studies over the past decade have uncovered strong evidence favouring direct cell strain and interstitial fluid-flow as the most likely stimuli for mechanosensation, instead of streaming potentials or hydrostatic pressure. These studies further support that shear stress induced by fluidflow is the predominant stimuli recognized by osteocytes, as opposed to direct mechanical strain by substrate stretching $[32,33,37,39,57,58]$. 
Osteocytes may sense loads via several mechanisms. Both cell body and dendritic processes have been proven to perceive mechanical forces. Several in vitro studies [33,59-61] have attempted to de- cipher the part of the cell - body or dendritic process - that is more sensitive to mechanical forces. Although it remains a controversial subject, the prevalent, widely accepted, hypothesis proposes that the osteocyte cell process is responsible for mechanosensation [62].

Several excellent papers on the mechanisms for the initial detection and conversion of a mechanical force into a biochemical signal, such as $[21,32,63]$ and references within these papers, have been written, and the reader is referred to these studies for many of the details. Integrins, cation non-selective channels and the bone cell primary cilium are proposed to be involved in the osteocyte perception process of the mechanical signal.

One critical transduction pathway consists of strengthening ligand-integrincytoskeleton linkages in response to a force. Integrins are a superfamily of cell adhesion receptors that bind to extracellular matrix ligands, cell-surface ligands, and soluble ligands. The transfer of forces across cell adhesions allows focused stresses applied on the surface membrane to affect distant sites, such as the mitochondria and nucleus $[22,56,64,65]$.

Ion channels, which are located in bone cell membranes, form strain-sensitive systems that respond to several stimuli, such as ligand binding, voltage changes, stretching and fluid shearing, via cellular ion fluxes. Several of these channels have been detected in osteocyte cultures: $\mathrm{Gd}^{3+}$ sensitive non-selective cation channel; the volume sensitive epithelial-like $\mathrm{Na}^{+}$channel ENaC; secondary driven $\mathrm{Ca}^{2}+$ channels, such as the voltage-dependent L-type channels or $\mathrm{Na}^{+} / \mathrm{Ca}^{2+}$ exchange channels; and $\mathrm{Cl}^{-}$and $\mathrm{K}^{+}$channels. Integrins and stretch-activated channels also seem to be linked. Hence, cell stretching may lead to an increase in lateral membrane tension, which activates mechanically gated ion channels, i.e., stretch-activated channels. Stretchactivated cation channels are also thought to be responsible for mechanotransduction in osteoblasts. [64,66-68].

Primary cilia are structures that project from the cell surface and deflect under fluidflow. Currently, research points to the follow- ing flow-induced cilia response: increase in cox-2 gene expression, prostaglandin E2 release (which is an important chemical mediator in the mechanotransduction process, as outlined in the following section) and an increase in the OPG/RANKL ratio. The cilia-based osteocyte response is independent of intracellular calcium. Many interesting aspects of the role of primary cilia in bone mechanotransduction remain to be studied $[30,69,70]$.

Although osteocyte sensing mechanisms have been individually presented, researchers strongly believe that these mechanisms are highly associated; therefore, there is no single transduction pathway [9]. 
The in vivo and in vitro osteocyte responses to load include the production of several biochemically relevant messengers $[57,71,72]$, such as $\mathrm{Ca}^{2+}$, nitric oxide and prostaglandin E2.

One of earliest osteocyte responses to mechanical stimulation is calcium $\left(\mathrm{Ca}^{2+}\right)$ exchange between the extracellular and intracellular medium. This response propagates to the neighbouring cells, suggesting that the cellular network communicates and synchronizes via this mechanism. This response initiates a number of essential down- stream signalling pathways, e.g. ATP, nitric oxide and prostaglandin E2 (PGE2) release $[9,60,73,74]$.

Nitric oxide (NO) and PGE2 are considered potent anabolic regulators of bone growth. Studies have shown $[75,76]$ that the inhibition of only one of the two rapidly released small molecules at the time of mechanical stimulation suppresses the osteogenic response to mechanical stimulation.

NO is responsible for stimulating bone formation by inhibiting osteoclast formation and inducing osteoblasts differentiation. This anabolic regulator is also responsible for maintaining the viability of osteocytes and enhancing PGE2 [77]. Klein-Nulend et al. [78] examined the effect of pulsating fluid flow $(0.5 \pm 0.02 \mathrm{~Pa}, 5 \mathrm{~Hz}$ and $0.4 \mathrm{~Pa} / \mathrm{s})$ stimulation on chicken calvarial osteocytes. NO showed a maximum effect after $5 \mathrm{~min}$, decreasing afterwards. PGE2 effect was significant after $10 \mathrm{~min}$, which was maintained throughout $60 \mathrm{~min}$.

PGE2 is an important signalling molecule because it not only stimulates osteogenic function in existing osteoblasts but also increases the production of osteoblasts by recruiting and promoting the differentiation of precursor cells. Another molecule that has similar effects to PGE2 on the signalling of the osteogenic process is the insulin-like growth factor I [9,32,78-82].

During bone remodelling, a cutting cone of osteoclasts, followed by a reversal or transition zone of osteoblast precursors and a closing cone of osteoblasts, constitute the basic multicellular units (BMU), which move in tandem. In modelling, bone resorption driven by osteoclasts and osteoblast-mediated bone formation actuate independently on different surfaces of the skeleton as bone is reshaping to adapt to different loading conditions [29,71,83-85].

\section{Bone strain in vivo}

The quantification of human normal bone strain is an important step in understanding the response of bone to mechanical stimuli [86]. One of the first contributions to this subject was made by Hert et al. [87], Hert et al. [88]. By applying loads to rabbit tibiae diaphysis using transcutaneous pins and Bowden cables, they showed that dynamic, but not static strains, increase bone formation. Today, the response of bone cells to mechanical stimuli is well accepted to be modulated by the parameters of the applied strain, namely, the magnitude, rate and duration of the applied load $[9,55,89]$. 
Although Hert et al. [88] could determine the magnitude of the applied load in their experiment, they could not determine either the physiological strains in that region or the strains that the loading engendered [86]. The in vivo measurement of strain in bone tissue surface was not possible until the development of strain gauges, the goldstandard for measuring bone strain [90-92]. The use of strain gauges on the bone surface was reportedly introduced as early as the mid-twentieth century $[86,93]$.

Following Roux's footprints, Frost [94] developed an important concept: the "mechanostat" for bone adaptation to strain. This theory proposes a mechanical usage window and introduces the concept of minimal effective strain (MES). Frost compiled his various works that concern mechanical stimuli for bone regeneration in a 2003 paper [95], which describes the "mechanostat" as follows (see Fig. 2): he claimed a threshold for disuse-mode remodelling (MESr), 50-100 $\mu \varepsilon$, below which bone is removed and weakened. He defined the modelling region (MESm) between 1000 and $1500 \mu \varepsilon$, where mechanically controlled modelling begins and could increase if strains exceed this upper limit. Frost believed that strain stimuli between MESr and MESm could define the region of naturally acceptable whole-bone strength relative to the typical peak voluntary mechanical load on a loadbearing bone during typical physical activities and the span of a normal "bone-strength/bone-load" ratio. According to this theory, the microdamage threshold (MESp) is approximately $3000 \mu \varepsilon$ and loads that can fracture a healthy young adult bone cause strains centred near 25,000 $\mu \varepsilon(\mathrm{Fx})$.

Even though several researchers [23,96-98] support Frost's MESm concept of an increase in bone mass and remodelling when a mechanical load surpasses a threshold, criticism has also been raised. Some researchers $[7,86]$ claim that Frost's theory is a qualitative theoretical construction of several hypotheses and that the precise threshold limits that control bone remodelling remain unknown. A dataset based on several studies was created to evaluate the ability of various types of vigorous physical activities to "stimulate bone formation" according to the MES concept (see Table 1). In all selected studies, the test subjects were healthy, young adult or middle- aged humans of both genders, and the peak strains were obtained by directly attaching strain gauges to the tibia bone surface.

An analysis of Table 1 indicates that of the vigorous activities considered, bicycle riding at 60 cycles/s produced the lower peak strain values both in compression and tension sites, with magnitudes on the order of 291 and $271 \mu \varepsilon$, respectively. Normal walking activity, depending on the type of floor or grade (levelled, uphill or downhill gait), can lead to compression bone strain values ranging from 308 to $950 \mu \varepsilon$. Table 1 also shows that, when considering the same type of physical activity and muscular contraction, different sites on the tibia present different local deformations.

Running can lead to compressive bone strains from $879 \mu \varepsilon$ during jogging to $2104 \mu \varepsilon$ during $17 \mathrm{~km} / \mathrm{h}$ sprints. The highest strain was registered during a forward jump and vertical drop, which led to compressive deformations of up to $3450 \mu \varepsilon$. In addition to the maxi- mum strain values mentioned, in vivo measurements of human tibiae strains do not seem to exceed $2000 \mu \varepsilon$, even during vigorous running activity.

The data presented in Table 1 suggest that the peak strain com- pressive values tend to be higher than the tension values, with the exception of walking and running downhill. 
Both the strain magnitude and strain rate are considered essential parameters in the stimuli process. In Table 1, the strain rates were again lower during bicycle riding at 60 $\mathrm{Hz}$, with both compressive and tensile values of approximately $5 \mathrm{~Hz}$. Higher strain rates were registered during sprint running, with values of up to 26 and $31 \mathrm{~Hz}$ in compression and tension, respectively. These data are in the physiological strain rate range claimed in other studies [9,55,89,99,100], between 1 and $60 \mathrm{~Hz}$.

The data in Table 1 should be considered an approximation of real values because the effect of muscle fatigue on the bone strains and strain rates, as has often been identified in vivo, cannot be excluded in all studies. However, physical activities, such as sprinting or running in a zigzag, forward jumping and vertical dropping, may increase bone formation if we consider these data to be physiological values and 1000 $\mu \varepsilon$ at $1 \mathrm{~Hz}$ cyclic mechanical loading is assumed as the MESm [101-103]. Importantly, only tibiae shaft measurements were considered, and conclusions based on these data should not be extrapolated to the spine and may or may not be valid for other bones in the body [98,104-106].

Normally a large portion of human daily routine includes events that are associated with far smaller strain magnitudes than vigorous physical activities, such as standing and sitting. According to Huang et al. [107], very low strains, those significantly smaller than $5 \mu \varepsilon$, at high frequency strains are constantly bombarding the human skeleton. This finding was confirmed by Fritton et al. [90], who counted the daily (12-24 h) strain events and showed that large strains (exceeding $1000 \mu \varepsilon$ ) seldom occur throughout the day and that very small strains (less than $10 \mu \varepsilon$ ) occur thousands of times per day. Thus, the importance of small strains in bone adaptation and/or bone maintenance needs to be assessed.

Rubin et al. [108] asserted that the strain magnitude and strain rate of bone are related. In this study, they noticed that cortical bone mass could be maintained via the application of a $800 \mu \varepsilon$ peak- induced load at a frequency of $3 \mathrm{~Hz}$ for $600 \mathrm{~s}$ per day. Furthermore, only $200 \mu \varepsilon$ was necessary to maintain cortical bone mass for the same loading regimen if the strain was applied at $30 \mathrm{~Hz}$. In a study by Weinbaum et al. [99], $250 \mu \varepsilon$ at $15 \mathrm{~Hz}$ produced a fluid shear stress that was 3.75 times that of a $1000 \mu \varepsilon$ at 1 $\mathrm{Hz}$ stimulus and exceeded the threshold for excitation. Moreover, Rubin et al. [108] showed that the combination of an even lower strain amplitude than the ones tested by [99], i.e., less than $10 \mu \varepsilon$, with a high-frequency physiological strain rate between 10 and $100 \mathrm{~Hz}$ could stimulate bone growth by doubling its formation rate. These findings led to the development of several studies based on the potential use of such stimuli [109-111].

These findings indicate that low-amplitude high-frequency postural strains due to muscular contractions could be as or even more effective in maintaining bone mass than high-amplitude low-frequency strains due to locomotion. This behaviour may explain why astronauts lose bone mass in a microgravity environment, where the need to maintain posture is absent, despite rigorous exercise, or why $3 \mathrm{~h} /$ day of quiet standing has been shown to prevent bone loss in bed rest patients $[90,112,113]$. 


\section{Test system for mechanical stimulation study}

Selecting the most suitable test model for a stimulation study of bone mechanical behaviour is very important. Several test systems are available and are grouped in four categories: in vivo, in vitro, ex vivo and in silico.

\subsection{In vivo}

For in vivo testing, although no species fulfils the requirements of an ideal animal model, the dog is perhaps described as having the most similar bone structure to humans. However, using companion animals for medical research is associated with ethical implications. Other species, such as sheep and pigs, have also been suggested. Some researchers have also shown a preference for using rats and mice as experimental animal models [114-118]. According to the literature, rabbits may be the least similar to humans in terms of bone structure and properties. When possible, other bone study test models should be used prior to in vivo experimentation because the latter is expensive, leads to animal sacrifice, presents a large degree of systemic complexity and often is not considered satisfactory for the investigation of the mechanism that underlies cellular processes in bone [119-122].

\section{In vitro and ex vivo}

In vitro bone research includes three main branches: cell culture, for which cells are mechanically or enzymatically harvested from tis- sue and proliferate in a suspension or attached to a surface or monolayer; tissue culture, for which tissue fragments are maintained with- out not necessarily preserving architecture; and organ culture, for which organs (in whole or in part) or tissues are maintained or grown in vitro [123]. Several methodologies to provide mechanical stimuli for experimental study are reviewed by Ehrlich et al. [86], Brown [124], Brown [125].

Since Glucksmann [126] first used in vitro bone cell cultures to study the effects of mechanical stimuli in bone formation, this system has been considered to be an acceptable and common approach. This test system was also adapted to meet the purposes of more specific research, such as the study of cell responsiveness to fluid flow, first via the development of the parallel plate flow chamber by Frangos et al. [127], as well as in a number of other studies $[47,128]$ that developed similar experimental devices. The advantage of using cell culture systems is that the local environment can be tightly controlled, such as ensuring the absence of growth hormones. A great number of molecular and biochemical tools are also available to ensure that experimental replicates are almost identical, which simplifies statistical analysis and quantification $[119,123,129]$.

The most common bone cell cultures used for in vitro mechanical stimulation experiments are osteoblastic (e.g., MC3T3-E1), osteocytic (e.g., MLO-Y4) and less often, 
osteoclastic-like cell cultures. Due to their availability and ease of use, osteoblast cell lines are used in many studies to infer osteocytes behaviour. While osteocytes are the descendants of osteoblasts and similarities would be expected for cells of the same lineage, these cells have distinct differences, particularly in their responses to mechanical loading $[9,32,33,130]$.

For studies of the osteocyte physiological response to mechanical loading, twodimensional cell culture conditions are arguably far too simple and hardly representative of the complex bone environment. This approach overlooks many parameters known to be essential for accurately reproducing the mechanotransduction process. Three- dimensional cell-growth environments have been developed in an at- tempt to overcome some cell culture disadvantages, mimic the physiological complexity of real tissue, and avoid the use of bone organ cultures [121]. Several materials have been tested as scaffolds, such as collagen glycosaminoglycan [131,132] and porous chitosan [133]. Un- der static culture conditions, cell proliferation in scaffolds is limited by diffusion, due to increases in the cell mass and decreases in the effective porosity resulting from matrix deposition. Fluid transport and cell distribution, as well as cell stimulation and differentiation may be improved via the use of bioreactors for three-dimensional scaffold systems [134,135]. Flow perfusion bioreactors are more commonly used than any other bioreactor for three-dimensional bone stimulation studies. These bioreactor systems pump culture medium through the scaffold's interconnected pores, which are held in place across the continuously circulating flow. These devices enable the close monitoring and precise control of several environmental conditions, such as the temperature, $\mathrm{pH}$, oxygen and nutrient supply inside the scaffold and removal of waste products and metabolites. They also provide a high degree of reproducibility and automation, which favours the development and maturation of bone cells in scaffolds [134,136,137].

An understanding of the behaviour and responses of cells cultured on scaffolds should guide the scaffold optimization process. The pore size, pore interconnectivity and total porosity are essential parameters for scaffold development. The pore size affects cell migration into the scaffold and influences the amount of fluid that reaches the cells. It also determines the mechanical load to which the cells are exposed, i.e., the wall shear stress and the hydrostatic wall pressure that acts on the cells [138-143].

In vivo, osteocytes are attached to their mineralized matrix either via tethering filaments or perhaps via integrin-based focal adhesions. When these cells are seeded on a stiff two-dimensional surface, they are not surrounded by a pericellular matrix. Thus, they will spread out and form only integrin-based attachments with the substrate. In three-dimensional cultures, the pores dimensions of the scaffold will influence the initial cell attachment levels and the morphology of attachment, such as a flat morphology (akin to a two-dimensional monolayer culture), which occurs for large pores, and a bridging morphology. The pore size affects the cell's ability to span the void space $[32,144,145]$.

Cell attachment can influence the dynamics of surface-cell-flow relationships and thus impact the magnitude of cytoskeletal deformations. According to Klein-Nulend et al. [32], round non-adherent osteocytes are more sensitive to mechanical stimuli than adherent ones. In a study by Jungreuthmayer et al. [143], three-dimensional 
culture conditions required lower fluid flow rates to obtain bone formation than two-dimensional culture conditions, i.e., the increased cell deformability leads to increased cellular shear stress sensitivity. One advantage of two-dimensional systems over three-dimensional cell-scaffolds systems is that cellular loss due to fluid shear stress investigations is not a major concern in two-dimensional systems. In these systems, the levels of shear stress required to induce cellular detachment are orders of magnitude greater than those expected to cause osteogenesis in vivo. In three-dimensional cell-scaffolds systems, if a cell adapts a bridging morphology type, it will experience greater levels of cytoskeletal deformation than a flat cell when subjected to the same flow conditions [146]. Furthermore, according to KleinNulend et al. [32], the flow-induced stimulus for two- dimensional cell cultures is the same on the cell process and cell body in nearly all experiments.

Although tremendous advances have been made in the development of threedimensional scaffold-based systems for bone cells studies that could reproduce both the formation of an organized bone-like matrix and cell-mediated substrate degradation, this methodology is also associated with limitations depending on the aim of a study $[121,136]$.

To study bone's physiological strain profile in vitro, the bone's natural microenvironment must be mimicked. The osteocyte mechanosensation response depends on the type of material to which they are attached. Hence, scaffolds that mimic the properties of native bone should be used. However, the osteocyte mechanical conditions in vivo are not clearly understood, which precludes the re- liable recreation of these conditions in an in vitro experiment. Variables such as the complex lacunacanalicular geometry and the distribution of the cell's focal adhesions play an important role in the osteocyte mecanotransduction process $[60,147,148]$.

The critical requirement for in vitro models that represent the physiological diversity and complexity of the bone formation process have led to the development of different test systems, such as bone organ cultures or ex vivo bone culture systems.

Organ culture has been used for more than 50 years in an at- tempt to bridge the gap between cell culture and in vivo models $[123,149,150]$. The pioneering work of Fell et al. [151] in this field is known worldwide.

Organ culture provides a model that is, in certain aspects, more similar to the in vivo situation. This testing system respects the bone's natural three-dimensional structure and retains the extracellular matrix, which allows normal cell-matrix attachment sites to be maintained. The conservation of the tissue architectural organization will most likely simulate the physiological distinct mechanical con- sequence of loading, such as strain, fluid shear stress, and streaming potentials. Another great advantage of using organ culture technology is that they are not as complex as the whole animal and local effects, such as mediators and mechanical stress, can be isolated from systemic ones, such as steroids, other hormones and toxins [89,120,149,152].

The main disadvantages of using organ cultures are (1) the loss of a vascular system, which limits the organ sample size that can be harvested; (2) explants cannot be used for experiments longer than $24 \mathrm{~h}$; and (3) the artificial environment created requires that the investigator exercises caution in the interpretation of the results and their 
extrapolation to an in vivo situation $[86,89,120,123,149,150]$.

In recent years, the evolution of bioreactor devices for the application of specific mechanical stimuli and controlled medium recirculation has favoured cell viability and prolonged culture time of bone explants [121]. A system that shows a successful applicability of these strategy was developed by Davies et al. [153]. In this ex vivo system, a mechanical loading and measurement system are combined with a cancellous bone diffusion culture-loading chamber named ZetOSTM. This bioreactor maintains bone biopsy cultures for extended periods of time whilst preserving the natural three-dimensional architecture and inter-cellular interactions of several cell types.

\section{In silico}

The use of conceptual and mathematical models has already proven valuable in bone research [154]. Advances in scientific knowledge, mathematical modelling, and computer technology has facilitated the integration of numerical equations into finite element models [155]. A variety of computational approaches [156-161] have been developed in an attempt to understand the mechanotransduction process and response to mechanical stimulus in bone, such as interstitial fluid flow [41,162] and direct cell strain [36].

A good example of the integration of in silico analysis with in vivo and in vitro studies is the work developed by Yang et al. [163]. The authors studied the strain field in mice tibiae using micro CT-based finite element analysis together with diaphyseal strain gauge measurements during in vivo dynamic compression loading. Furthermore, as suggested by Webster et al. [164], future computational approaches should focus on merging models from different scales into a fully integrated multiscale modelling approach, which would enhance both the predictive and descriptive ability of computationally models and consequently facilitate the generation of new hypotheses and new experimental studies.

\section{Conclusion}

The scientific community has long recognized the importance of mechanical loading conditions in defining the mass and structure of bone. Bending moment stimuli are experienced by and transmitted along long bones via a combination of its physiological curvature, gravitational load (body weight) and the load applied by balanced muscle activities. Hence, muscle and bone are coupled as a functional unit. During mechanotransduction, osteocytes play the role of sensory cells within the bone, and their response is most likely mediated by strain-derived fluid flow shear stress through the lacuno-canalicular network. Osteocytes will respond to this mechanical stimuli by opening stretch-activated ion channels and increasing the levels of intracellular $\mathrm{Ca}^{2+}$ and protein Kinase $\mathrm{C}$, which consequently stimulate the release of potent anabolic regulators of bone growth, such as NO and PGE2. 
The mechanical stimulus strain magnitude and rate are important parameters. Low frequency, high magnitude strains occur during vigorous activities, such as running and jumping, and exert a recognized positive effect on bone formation/remodelling. Conversely, the relevance of high frequency, low magnitude strains associated with events such as standing or sitting as bone mechanical stimuli is now starting to be taken into consideration.

Isolated cell lines in mechanical stimulation studies are important to investigate the behaviour of individual bone cell populations during mechanotransduction. For studies of the bone mechanical and biological environments in vivo, two-dimensional osteoblast- or osteocyte-like cell cultures and the use of cells scaffolds do not fully mimic the real bone environment, which is an organ system with complex and distinct cell interactions. Thus, defining the type of study and the variables that need be included in the system is important to select the proper test model.

With this paper, we attempt to clarify important notions related to the adaptation behaviour of bone to external load stimuli. Although mechanical forces clearly affect the bone's behaviour, this relationship remains poorly understood. Continued studies of both the mechanical (e.g., bone muscle interactions) and biological fields (e.g., mechanisms and pathways underlying bone remodelling and mechanotransduction) are necessary. Moreover, biomechanical cross-talk should not be neglected. New research tools, such as advanced algorithms and techniques to assess the mechanical environment of bone in vivo, should allow integrated approaches to capture the complex dynamics of bone biomechanical behaviour. A better understanding of bone's response process to mechanical stimuli should provide new insights into diseases, such as osteoporosis, hyperparathyroidism, hyperthyroidism, Paget's disease and osteopetrosis.

\section{Conflicts of interest}

None declared.

\section{Ethical approval}

Not required for this study.

\section{Acknowledgements}

We acknowledge support from the Foundation for Science and Technology (FCT), Lisbon, Portugal, through Project PEst- C/CTM/LA0025/2013 and research grant SFRH/BD/87089/2012 (NR).

\section{Bibliography}

1. Galilei G. Discorsi e dimostrazioni matematiche intorno a due nuove scienze attenenti alla meccanica ed ai movimenti locali. 1st ed. Leida: Società 
Editrice Fiorentina; 1638.

2. von Meyer GH. Die architektur der spongiosa. Arch Anat Physiol Wiss Med 1867;34:615-28.

3. Culmann K. Die graphische statik. Zürich: Meyer \& Zeller; 1866.

4. Roux W. Die entwicklungsmechanik; ein neuer Zweig der biologischen Wis- senschaft. Roux, Vorträge und Aufsätze, part I. Leipzig: Engelmann; 1905.

5. Skedros JG, Brand RA. Biographical sketch: Georg Hermann von Meyer (1815-1892). Clin Orthop Relat Res 2011;469:3072-6.

6. Carter DR. Mechanical loading histories and cortical bone remodeling. Calcif Tis- sue Int 1984;36:S19-24.

7. Huiskes R. If bone is the answer, then what is the question. J Anat 2000;197:145- 56.

8. Wolff J. Das gesetz der transformation der knochen. Berlin: Verlag von August Hirschwald; 1892.

9. Duncan RL, Turner $\mathrm{CH}$. Mechanotransduction and the functional response of bone to mechanical strain. Calcif Tissue Int 1995;57:344-58.

10. Ahn AC, Grodzinsky AJ. Relevance of collagen piezoelectricity to "Wolff 's Law": a critical review. Med Eng Phys 2009;31:733-41.

11. Skerry TM. One mechanostat or many? Modifications of the site-specific re- sponse of bone to mechanical loading by nature and nurture. J Musculoskel Neu- ron Interact 2006;6:122-7.

12. Burr DB. Muscle strength, bone mass, and age-related bone loss. J Bone Miner Res 1997;12:1547-51.

13. Bakker AD, Soejima K, Klein-Nulend J, Burger EH. The production of nitric oxide and prostaglandin E2 by primary bone cells is shear stress dependent. J Biomech 2001;34:671-7.

14. Duda GN, Heller M, Albinger J, Schulz O, Schneider E, Claes L. Influence of muscle forces on femoral strain distribution. J Biomech 1998;31:841-6.

15. Rittweger J, Reeves ND, Narici MV, Belavý DL, Maganaris CN, Maffulli N. Persist- ing side-to-side differences in bone mineral content, but not in muscle strength and tendon stiffness after anterior cruciate ligament reconstruction. Clin Physiol Funct Imaging 2011;31:73-9.

16. Sievänen H, Heinonen A, Kannus P. Adaptation of bone to altered loading envi- ronment: a biomechanical approach using X-ray absorptiometric data from the patella of a young woman. Bone 1996;19:55-9.

17. Schönau E, Werhahn E, Schiedermaier U, Mokow E, Schiessl H, Scheidhauer K, et al. Influence of muscle strength on bone strength during childhood and ado- lescence. Horm Res 1996;45:63-6.

18. Klein-Nulend J, Bacabac RG, Mullender MG. Mechanobiology of bone tissue. Pathol Biol 2005;53:576-80.

19. Pauwels F. Biomechanics of the Locomotor Apparatus. Berlin: Springer Berlin Heidelberg; 1980.

20. Munih M, Kralj A, Bajd T. Bending moments in lower extremity bones for two standing postures. J Biomed Eng 1992;14:293-302. 
21. Lanyon LE. Using functional loading to influence bone mass and architecture: ob- jectives, mechanisms, and relationship with estrogen of the mechanically adap- tive process in bone. Bone 1996;18:S37-43.

22. Aarden EM, Nijweide PJ, Burger EH. Function of osteocytes in bone. J Cell Biochem 1994;55:287-99.

23. Rubin CT, McLeod KJ, Bain SD. Functional strains and cortical bone adaptation: epigenetic assurance of skeletal integrity. J Biomech 1990;23:4354.

24. Turner $\mathrm{CH}$, Pavalko FM. Mechanotransduction and functional response of the skeleton to physical stress: the mechanisms and mechanics of bone adaptation. J Orthop Sci 1998;3:346-55.

25. Waung JA, Bassett JHD, Williams GR. Thyroid hormone metabolism in skele- tal development and adult bone maintenance. Trends Endocrinol Metab 2012;23:155-62.

26. Cauley JA. Estrogen and bone health in men and women. Steroids 2015;99:11- 15.

27. Elefteriou F, Campbell P, Ma Y. Control of bone remodeling by the peripheral sympathetic nervous system. Calcif Tissue Int 2014;94:140-51.

28. Redlich K, Smolen JS. Inflammatory bone loss: pathogenesis and therapeutic in- tervention. Nat Rev Drug Discov 2012;11:234-50.

29. Manolagas SC, Parfitt AM. What old means to bone. Trends Endocrinol Metab 2010;21:369-74.

30. Temiyasathit $S$, Jacobs $C R$. Osteocyte primary cilium and its role in bone mechan- otransduction. Ann N Y Acad Sci 2010;1192:422-8.

31. Isaacson BM, Bloebaum RD. Bone bioelectricity: what have we learned in the past 160 years? J Biomed Mater Res 2010;95:1270-9.

32. Klein-Nulend J, Bakker AD, Bacabac RG, Vatsa A, Weinbaum S. Mechanosensation and transduction in osteocytes. Bone 2013;54:182-90.

33. Rath Bonivtch A, Bonewald LF, Nicolella DP. Tissue strain amplification at the osteocyte lacuna: a microstructural finite element analysis. J Biomech 2007;40:2199-206.

34. Vaughan TJ, Verbruggen SW, McNamara LM. Are all osteocytes equal? Multiscale modelling of cortical bone to characterise the mechanical stimulation of osteo- cytes. Int J Numer Method Biomed Eng 2013;29:1361-72.

35. McGarry JG, Klein-Nulend J, Mullender MG, Prendergast PJ. A comparison of strain and fluid shear stress in stimulating bone cell responsesa computational and experimental study. FASEB J 2005;19:482-4.

36. Wang L, Dong J, Xian CJ. Strain amplification analysis of an osteocyte under static and cyclic loading: a finite element study. Biomed Res Int 2015;2015:1-14.

37. Gardinier JD, Townend CW, Jen K-P, Wu Q, Duncan RL, Wang L. In situ per- meability measurement of the mammalian lacunar-canalicular system. Bone 2010;46:1075-81.

38. Ajubi NE, Klein-Nulend J, Nijweide PJ, Vrijheid-Lammers T, Alblas MJ, 
Burger EH. Pulsating fluid flow increases prostaglandin production by cultured chicken osteocytes-a cytoskeleton-dependent process. Biochem Biophys Res Commun 1996;225:62-8.

39. Bacabac RG, Smit TH, Mullender MG, Dijcks SJ, Van Loon JJWA, KleinNulend J. Nitric oxide production by bone cells is fluid shear stress rate dependent. Biochem Biophys Res Commun 2004;315:823-9.

40. Piekarski K. Transport mechanism operating between blood supply and osteo- cytes in long bones. Nature 1977;269:80-2.

41. Verbruggen SW, Vaughan TJ, McNamara LM. Fluid flow in the osteocyte me- chanical environment: a fluid-structure interaction approach. Biomech Model Mechanobiol 2014;13:85-97.

42. Morris HL, Reed CI, Haycock JW, Reilly GC. Mechanisms of fluid-flowinduced matrix production in bone tissue engineering. Proc Inst Mech Eng H J Eng Med 2010;224:1509-21.

43. Delaine-Smith RM, MacNeil S, Reilly GC. Matrix production and collagen struc- ture are enhanced in two types of osteogenic progenitor cells by a simple fluid shear stress stimulus. Eur Cell Mater 2012;24:162-74.

44. Young Y-N, Espinha LC, Nguyen AM, Jacobs CR. Multiscale modeling of primary cilia. In: De S, Hwang W, Kuhl E, editors. Multiscale modeling in biomechanics and mechanobiology. Springer; 2015. p. 87-110.

45. Donahue TLH, Haut TR, Yellowley CE, Donahue HJ, Jacobs CR. Mechanosensitivity of bone cells to oscillating fluid flow induced shear stress may be modulated by chemotransport. J Biomech 2003;36:1363-71.

46. Case N, Sen B, Thomas JA, Styner M, Xie Z, Jacobs CR, et al. Steady and os- cillatory fluid flows produce a similar osteogenic phenotype. Calcif Tissue Int 2011;88:189-97.

47. Jacobs CR, Yellowley CE, Davis BR, Zhou Z, Cimbala JM, Donahue HJ. Differential effect of steady versus oscillating flow on bone cells. J Biomech 1998;31:969-76.

48. Hastings G, Mahmud F. Electrical effects in bone. J Biomed Eng 1988;10:515-21.

49. Starkebaum W, Pollack SR, Korostoff E. Midroelectrode studies of stress- generated potentials in four-point bending of bone. J Biomed Mater Res 1979;13:729-51.

50. Salzstein RA, Pollack SR, Mak AFT, Petrov N. Electromechanical potentials in cor- tical bone-I. A continuum approach. J Biomech 1987;20:261-70.

51. Salzstein RA, Pollack SR. Electromechanical potentials in cortical boneII. Exper- imental analysis. J Biomech. 1987;20:271-80.

52. Yasuda I. The classic: fundamental aspects of fracture treatment, reprinted from J Kyoto Med Soc, 4:395-406, 1953. Clin Orthop Relat Res 1977;124:5-8.

53. Fukada E, Yasuda I. On the piezoelectric effect of bone. J Physical Soc Jpn 1957;12:1158-62. 
54. Marino AA, Becker RO, Soderholm SC. Origin of the piezoelectric effect in bone. Calcif Tissue Res 1971;8:177-80.

55. Minary-Jolandan M, Yu M-F. Nanoscale characterization of isolated individ- ual type I collagen fibrils: polarization and piezoelectricity. Nanotechnology 2009;20:085706.

56. Lemaire T, Capiez-Lernout E, Kaiser J, Naili S, Rohan E, Sansalone V. A multiscale theoretical investigation of electric measurements in living bone. Bull Math Biol 2011;73:2649-77.

57. Schaffler MB, Cheung W-Y, Majeska R, Kennedy O. Osteocytes: master orchestra- tors of bone. Calcif Tissue Int 2013;94:1-20.

58. Iolascon G, Resmini G, Tarantino U. Mechanobiology of bone. Aging Clin Exp Res 2013;25:3-7.

59. Han Y, Cowin SC, Schaffler MB, Weinbaum S. Mechanotransduction and strain amplification in osteocyte cell processes. Proc Natl Acad Sci USA 2004;101:16689-94.

60. Adachi T, Aonuma Y, Tanaka M, Hojo M, Takano-Yamamoto T, Kamioka H. Cal- cium response in single osteocytes to locally applied mechanical stimulus: dif- ferences in cell process and cell body. J Biomech 2009;42:198995.

61. Thi MM, Suadicani SO, Schaffler MB, Weinbaum S, Spray DC. Mechanosensory responses of osteocytes to physiological forces occur along processes and not cell body and require $\alpha \mathrm{V} \beta 3$ integrin. Proc Natl Acad Sci 2013;110:21012-17.

62. Thi MM, Suadicani SO, Schaffler MB, Weinbaum S, Spray DC. Mechanosensory responses of osteocytes to physiological forces occur along processes and not cell body and require $\alpha \mathrm{V} \beta 3$ integrin. Proc Natl Acad Sci USA 2013;110:21012-17.

63. Robling AG, Turner CH. Mechanical signaling for bone modeling and remodeling. Crit Rev Eukaryot Gene Exp 2009;19:319-38.

64. Ross TD, Coon BG, Yun S, Baeyens N, Tanaka K, Ouyang M, et al. Integrins in mechanotransduction. Curr Opin Cell Biol 2013;25:613-18.

65. Ozcivici E, Luu YK, Adler B, Qin Y-X, Rubin J, Judex S, et al. Mechanical signals as anabolic agents in bone. Nat Rev Neurol 2010;6:50-9.

66. Mikuni-Takagaki Y, Naruse K, Azuma Y, Miyauchi A. The role of calcium channels in osteocyte function. J Musculoskel Neuron Interact 2002;2:252-5.

67. Liedert A, Kaspar D, Blakytny R, Claes L, Ignatius A. Signal transduction pathways involved in mechanotransduction in bone cells. Biochem Biophys Res Commun 2006;349:1-5.

68. Rawlinson SCF, Pitsillides AA, Lanyon LE. Involvement of different ion chan- nels in osteoblasts' and osteocytes' early responses to mechanical strain. Bone 1996;19:609-14.

69. Malone AMD, Anderson CT, Tummala P, Kwon RY, Johnston TR, Stearns T, et al. Primary cilia mediate mechanosensing in bone cells by a calciumindependent mechanism. Proc Natl Acad Sci USA 2007;104:13325-30. 
70. Delaine-Smith RM, Sittichokechaiwut A, Reilly GC. Primary cilia respond to fluid shear stress and mediate flow-induced calcium deposition in osteoblasts. FASEB J 2014;28:430-9.

71. Pajevic PD. Recent progress in osteocyte research. Endocrinol Metab 2013;28:255-61.

72. Hum JM, Day RN, Bidwell JP, Wang Y, Pavalko FM. Mechanical loading in osteo- cytes induces formation of a Src/Pyk2/MBD2 complex that suppresses anabolic gene expression. PLoS One 2014;9:e97942.

73. Lu XL, Huo B, Park M, Guo XE. Calcium response in osteocytic networks under steady and oscillatory fluid flow. Bone 2012;51:466-73.

74. Lemaire T, Naili S. Possible role of calcium permselectivity in bone adaptation. Med Hypotheses 2012;78:367-9.

75. Fox SW, Chambers TJ, Chow JW. Nitric oxide is an early mediator of the increase in bone formation by mechanical stimulation. Am J Physiol Endocrinol Metab 1996;270:E955-60.

76. Chow JWM, Fox SW, Lean JM, Chambers TJ. Role of nitric oxide and prostaglandins in mechanically induced bone formation. J Bone Miner Res 1998;13:1039-44.

77. Klein-Nulend J, Van Oers RFM, Bakker AD, Bacabac RG. Nitric oxide signaling in mechanical adaptation of bone. Osteoporos Int 2014;25:1427-37.

78. Klein-Nulend J, Semeins CM, Ajubi NE, Nijweide PJ, Burger EH. Pulsating fluid flow increases nitric oxide (NO) synthesis by osteocytes but not periosteal fibroblasts-correlation with prostaglandin upregulation. Biochem Biophys Res Commun 1995;217:640-8.

79. Vatsa A, Mizuno D, Smit TH, Schmidt CF, MacKintosh FC, Klein-Nulend J. Bio imaging of intracellular NO production in single bone cells after mechanical stimulation. J Bone Miner Res 2006;21:1722-8.

80. Tan SD, de Vries TJ, Kuijpers-Jagtman AM, Semeins CM, Everts V, KleinNulend J. Osteocytes subjected to fluid flow inhibit osteoclast formation and bone resorp- tion. Bone 2007;41:745-51.

81. Vezeridis PS, Semeins CM, Chen Q, Klein-Nulend J. Osteocytes subjected to pul- sating fluid flow regulate osteoblast proliferation and differentiation. Biochem Biophys Res Commun 2006;348:1082-8.

82. Dirckx N, Hul M, Maes C. Osteoblast recruitment to sites of bone formation in skeletal development, homeostasis, and regeneration. Birth Defects Res C Em- bryo Today 2013;99:170-91.

83. Hambli R, Rieger R. Physiologically based mathematical model of transduc- tion of mechanobiological signals by osteocytes. Biomech Model Mechanobiol 2012;11:83-93.

84. Robling AG, Castillo AB, Turner $\mathrm{CH}$. Biomechanical and molecular regulation of bone remodeling. Annu Rev Biomed Eng 2006;8:455-98.

85. Sims NA, Vrahnas C. Regulation of cortical and trabecular bone mass by commu- nication between osteoblasts, osteocytes and osteoclasts. Arch Biochem Biophys 2014;561:22-8. 
86. Ehrlich PJ, Lanyon LE. Mechanical strain and bone cell function: a review. Osteo- poros Int 2002;13:688-700.

87. Hert J, Liskova M, Landrgot B. Influence of the long-term, continuous bending on the bone an experimental study on the tibia of the rabbit. Folia Morphol 1969;17:389.

88. Hert J, Liskova M, Landa J. Reaction of bone to mechanical stimuli 1. Continuous and intermittent loading of tibia in rabbit. Folia Morphol. 1971;19:290-300.

89. Kunnel JG, Gilbert JL, Stern PH. In vitro mechanical and cellular responses of neonatal mouse bones to loading using a novel micromechanicaltesting device. Calcif Tissue Int 2002;71:499-507.

90. Fritton SP, McLeod KJ, Rubin CT. Quantifying the strain history of bone: spatial uniformity and self-similarity of low-magnitude strains. J Biomech 2000;33:317-25.

91. Hoshaw SJ, Fyhrie DP, Takano Y, Burr DB, Milgrom C. A method suitable for in vivo measurement of bone strain in humans. J Biomech 1997;30:521-4.

92. Lanyon LE, Hampson WGJ, Goodship AE, Shah JS. Bone deformation recorded in vivo from strain gauges attached to the human tibial shaft. Acta Orthop Scand 1975;46:256-68.

93. Mikic' B, Carter DR. Bone strain gage data and theoretical models of functional adaptation. J Biomech 1995;28:465-9.

94. Frost HM. Bone "mass" and the "mechanostat": a proposal. Anat Rec 1987; 219:1-9.

95. Frost HM. Bone's mechanostat: a 2003 update. Anat Rec 2003;275:1081101.

96. Burr DB, Milgrom C, Fyhrie D, Forwood M, Nyska M, Finestone A, et al. In vivo measurement of human tibial strains during vigorous activity. Bone 1996;18:405-10.

97. Ekenman I, Halvorsen K, Westblad P, Fellãnder-Tsai L, Rolf C. Local bone defor- mation at two predominant sites for stress fractures of the tibia: an in vivo study. Foot Ankle Int 1998;19:479-84.

98. Milgrom C, Finestone A, Levi Y, Simkin A, Ekenman I, Mendelson S, et al. Do high impact exercises produce higher tibial strains than running? $\mathrm{Br} \mathrm{J}$ Sports Med 2000;34:195-9.

99. Weinbaum S, Cowin SC, Zeng Y. A model for the excitation of osteocytes by mechanical loading-induced bone fluid shear stresses. J Biomech 1994;27:339- 60 .

100. Henstock JR, Rotherham M, Rose JB, El Haj AJ. Cyclic hydrostatic pressure stim- ulates enhanced bone development in the foetal chick femur in vitro. Bone 2013;53:468-77.

101. Poliachik SL, Threet D, Srinivasan S, Gross TS. 32 wk old C3H/HeJ mice actively respond to mechanical loading. Bone 2008;42:653-9.

102. Rubin CT, Lanyon LE. Regulation of bone mass by mechanical strain magnitude. Calcif Tissue Int 1985;37:411-17. 
103. Turner CH, Forwood MR, Rho J-Y, Yoshikawa T. Mechanical loading thresholds for lamellar and woven bone formation. J Bone Miner Res 1994;9:87-97.

104. Al Nazer R, Rantalainen T, Heinonen A, Sievänen H, Mikkola A. Flexible multi- body simulation approach in the analysis of tibial strain during walking. J Biomech 2008;41:1036-43.

105. Milgrom C, Radeva-Petrova DR, Finestone A, Nyska M, Mendelson $\mathrm{S}$, Benjuya $\mathrm{N}$, et al. The effect of muscle fatigue on in vivo tibial strains. J Biomech 2007;40:845-50.

106. Milgrom C, Finestone A, Simkin A, Ekenman I, Mendelson S, Millgram $M$, et al. In vivo strain measurements to evaluate the strengthening potential of exercises on the tibial bone. J Bone Joint Surg Br 2000;82:591-4.

107. Huang RP, Rubin CT, McLeod KJ. Changes in postural muscle dynamics as a func- tion of age. J Gerontol A Biol Sci Med Sci 1999;54:B352-7.

108. Rubin CT, Sommerfeldt DW, Judex S, Qin Y-X. Inhibition of osteopenia by low magnitude, high-frequency mechanical stimuli. Drug Discov Today 2001; 6:848-58.

109. Judex S, Rubin CT. Is bone formation induced by high-frequency mechanical sig- nals modulated by muscle activity? J Musculoskel Neuron Interact 2010;10:3-11.

110. Afzal SY, Wender AR, Jones MD, Fung EB, Pico EL. The effect of low magni- tude mechanical stimulation (LMMS) on bone density in patients with Rett syn- drome: a pilot and feasibility study. J Pediatr Rehabil Med 2014;7:167-78.

111. Padilla F, Puts R, Vico L, Raum K. Stimulation of bone repair with ultrasound: a review of the possible mechanic effects. Ultrasonics 2014;54:1125-45.

112. Dionyssiotis Y, Stathopoulos K, Trovas G, Papaioannou N, Skarantavos G, Papagelopoulos P. Impact on bone and muscle area after spinal cord injury. BoneKEy Rep 2015:4.

113. Lloyd SA, Lang CH, Zhang Y, Paul EM, Laufenberg LJ, Lewis GS, et al. Interdepen- dence of muscle atrophy and bone loss induced by mechanical unloading. J Bone Miner Res 2014;29:1118-30.

114. Hsieh Y-F, Robling AG, Ambrosius WT, Burr DB, Turner CH. Mechanical loading of diaphyseal bone in vivo: the strain threshold for an osteogenic response varies with location. J Bone Miner Res 2001;16:2291-7.

115. Noble BS, Peet N, Stevens HY, Brabbs A, Mosley JR, Reilly GC, et al. Mechanical loading: Biphasic osteocyte survival and targeting of osteoclasts for bone de- struction in rat cortical bone. Am J Physiol-Cell Physiol 2003;284:C934-43.

116. Robling AG, Niziolek PJ, Baldridge LA, Condon KW, Allen MR, Alam I, et al. Mechanical stimulation of bone in vivo reduces osteocyte expression of Sost/sclerostin. J Biol Chem 2008;283:5866-75.

117. Raab-Cullen DM, Akhter MP, Kimmel DB, Recker RR. Periosteal 
bone for- mation stimulated by externally induced bending strains. J Bone Miner Res 1994;9:1143-52.

118. Moustafa A, Sugiyama T, Saxon LK, Zaman G, Sunters A, Armstrong VJ, et al. The mouse fibula as a suitable bone for the study of functional adaptation to me- chanical loading. Bone 2009;44:930-5.

119. Pearce A, Richards RG, Milz S, Schneider E, Pearce SG. Animal models for implant biomaterial research in bone: a review. Eur Cell Mater 2007;13:1-10.

120. Jones DB, Broeckmann E, Pohl T, Smith EL. Development of a mechanical testing and loading system for trabecular bone studies for long term culture. Eur Cell Mater 2003;5:48-59.

121. Papadimitropoulos A, Scherberich A, Guven S, Theilgaard N, Crooijmans HJ, Santini F, et al. A 3D in vitro bone organ model using human progenitor cells. Eur Cell Mater 2011;21:445-58.

122. Meakin LB, Price JS, Lanyon LE. The contribution of experimental in vivo models to understanding the mechanisms of adaptation to mechanical loading in bone. Front Endocrinol 2014;5:1-13.

123. Davies CM, Jones DB, Stoddart MJ, Koller K, Smith E, Archer CW, et al. Mechan- ically loaded ex vivo bone culture system 'Zetos': systems and culture prepara- tion. Eur Cell Mater 2006;11:57-75.

124. Brown TD. Techniques for mechanical stimulation of cells in vitro: a review. J Biomech 2000;33:3-14.

$125 . \quad$ Brown TD. Devices and techniques for in vitro mechanical stimulation of bone cells. Bone mechanics handbook. Cowin SC, editor. 2nd ed., Florida: CRC Press; 2001.27-1-2.

126. Glucksmann A. The role of mechanical stresses in bone formation in vitro. J Anat 1942;76:231-9.

127. Frangos JA, McIntire LV, Eskin SG. Shear stress induced stimulation of mam- malian cell metabolism. Biotechnol Bioeng 1988;32:1053-60.

128. Nauman EA, Risic KJ, Keaveny TM, Satcher RL. Quantitative assessment of steady and pulsatile flow fields in a parallel plate flow chamber. Ann Biomed Eng 1999;27:194-9.

129. Huesa C, Helfrich MH, Aspden RM. Parallel-plate fluid flow systems for bone cell stimulation. J Biomech 2010;43:1182-9.

130. Kadow-Romacker A, Hoffmann JE, Duda G, Wildemann B, Schmidmaier G. Effect of mechanical stimulation on osteoblast-and osteoclastlike cells in vitro. Cells Tissues Organs 2008;190:61-8.

131. Chang Y-H, Brady RT, Brennan O, O’Brien FJ. A 3D environment influences os- teocyte function. BMC proceedings. Dublin, Ireland: BioMed Central Ltd; 2015.p. A7.

132. Keogh MB, O’Brien FJ, Daly JS. A novel collagen scaffold supports hu- man osteogenesis-applications for bone tissue engineering. Cell Tissue Res 2010;340:169-77. 
133. Su W-T, Wang Y-T, Chou C-M. Optimal fluid flow enhanced mineralization of MG-63 cells in porous chitosan scaffold. J Taiwan Inst Chem Eng 2014; 45:1111-18.

134. Plunkett N, O'Brien FJ. Bioreactors in tissue engineering. Technol Health Care 2011;19:55-69.

135. Porter BD, Lin ASP, Peister A, Hutmacher D, Guldberg RE. Noninvasive image analysis of $3 \mathrm{D}$ construct mineralization in a perfusion bioreactor. Biomaterials 2007;28:2525-33.

136. Haycock JW. 3D cell culture: a review of current approaches and techniques. In: Haycock JW, editor. 3D cell culture. Springer; 2011. p. 1-15.

137. Vetsch JR, Müller R, Hofmann S. The evolution of simulation techniques for dynamic bone tissue engineering in bioreactors. J Tissue Eng Regen Med 2013.

138. Murphy CM, Haugh MG, O'Brien FJ. The effect of mean pore size on cell attach- ment, proliferation and migration in collagenglycosaminoglycan scaffolds for bone tissue engineering. Biomaterials 2010;31:461-6.

139. O’Brien FJ, Harley BA, Waller MA, Yannas IV, Gibson LJ, Prendergast PJ. The effect of pore size on permeability and cell attachment in collagen scaffolds for tissue engineering. Technol Health Care 2007;15:3-17.

140. Murphy CM, O’Brien FJ, Little DG, Schindeler A. Cell-scaffold interactions in the bone tissue engineering triad. Eur Cell Mater 2013;26:12032.

141. Cartmell SH, Porter BD, García AJ, Guldberg RE. Effects of medium perfusion rate on cell-seeded three-dimensional bone constructs in vitro. Tissue Eng 2003;9:1197-203.

142. McCoy RJ, Jungreuthmayer C, O’Brien FJ. Influence of flow rate and scaffold pore size on cell behavior during mechanical stimulation in a flow perfusion bioreac- tor. Biotechnol Bioeng 2012;109:1583-94.

143. Jungreuthmayer C, Jaasma MJ, Al-Munajjed AA, Zanghellini J, Kelly DJ, O'Brien FJ. Deformation simulation of cells seeded on a collagen-GAG scaffold in a flow per- fusion bioreactor using a sequential 3D CFDelastostatics model. Med Eng Phys 2009;31:420-7

144. McCoy RJ, O’Brien FJ. Visualizing feasible operating ranges within tissue engi- neering systems using a "windows of operation" approach: a perfusion-scaffold bioreactor case study. Biotechnol Bioeng 2012;109:3161-71.

145. O’Brien FJ, Harley BA, Yannas IV, Gibson LJ. The effect of pore size on cell adhe- sion in collagen-GAG scaffolds. Biomaterials 2005;26:433-41.

146. McCoy RJ, O'Brien FJ. Influence of shear stress in perfusion bioreactor cultures for the development of three-dimensional bone tissue constructs: a review. Tissue Eng Part C Rev 2010;16:587-601.

147. Bonewald LF. The amazing osteocyte. J Bone Miner Res 2011;26:229-38.

148. Mauney JR, Sjostorm S, Blumberg J, Horan R, O’leary JP, Vunjak- 
Novakovic G, et al. Mechanical stimulation promotes osteogenic differentiation of human bone marrow stromal cells on 3-D partially demineralized bone scaffolds in vitro. Calcif Tissue Int 2004;74:458-68.

149. Meghji S, Hill PA, Harris M. Bone organ cultures. In: Arnett TR, Henderson B, editors. Methods in bone biology. 1st ed London: Springer; 1998. p. 106-26.

150. David V, Guignandon A, Martin A, Malaval L, Lafage-Proust M-H, Rattner A, et al. Ex vivo bone formation in bovine trabecular bone cultured in a dy- namic 3D bioreactor is enhanced by compressive mechanical strain. Tissue Eng 2008;14:117-26.

151. Fell HB, Mellanby E. The effect of hypervitaminosis A on embryonic limb-bones cultivated in vitro. J Physiol 1952;116:320-49.

152. Pitsillides AA, Rawlinson SCF. Using cell and organ culture models to analyze responses of bone cells to mechanical stimulation. In: Helfrich MH, Ral- ston SH, editors. Bone research protocols. 2nd ed. New York: Springer; 2012. p. 593-619.

153. Davies CM, Jones DB, Alini M, Archer C, Richards RG. Ex-vivo trabecular bone percolation system: development for evaluation of implant surfaces. Eur Cell Mater 2001;2:63.

154. Defranoux NA, Stokes CL, Young D, Kahn AJ. In silico modeling and simulation of bone biology: a proposal. J Bone Miner Res 2005;20:1079-84.

155. Colloca M, Blanchard R, Hellmich C, Ito K, van Rietbergen B. A multiscale analyt- ical approach for bone remodeling simulations: linking scales from collagen to trabeculae. Bone 2014;64:303-13.

156. Idhammad A, Abdali A, Alaa N. Computational simulation of the bone remod- eling using the finite element method: an elastic-damage theory for small dis- placements. Theor Biol Med Model 2013;10:1-11.

157. Schulte FA, Ruffoni D, Lambers FM, Christen D, Webster DJ, Kuhn $\mathrm{G}$, et al. Local mechanical stimuli regulate bone formation and resorption in mice at the tissue level. PLoS One 2013;8:e62172.

158. Geris L, Vander Sloten J, Van Oosterwyck H. In silico biology of bone mod- elling and remodelling: regeneration. Philos Trans R Soc A Math Phys Eng Sci 2009;367:2031-53.

159. Levchuk A, Zwahlen A, Weigt C, Lambers FM, Badilatti SD, Schulte FA, et al. The clinical biomechanics award 2012-presented by the European society of biome- chanics: large scale simulations of trabecular bone adaptation to loading and treatment. Clin Biomech 2014;29:355-62.

160. Birkhold AI, Razi H, Duda GN, Weinkamer R, Checa S, Willie BM. Mineralizing surface is the main target of mechanical stimulation independent of age: 3D dynamic in vivo morphometry. Bone 2014;66:15-25.

161. Hambli R. Connecting mechanics and bone cell activities in the bone remod- eling process: an integrated finite element modeling. Front Bioeng Biotechnol 2014;2:1-12.

162. Kameo Y, Adachi T. Interstitial fluid flow in canaliculi as a 
mechanical stim- ulus for cancellous bone remodeling: in silico validation. Biomech Model Mechanobiol 2014;13:851-60.

163. Yang H, Butz KD, Duffy D, Niebur GL, Nauman EA, Main RP. Characterization of cancellous and cortical bone strain in the in vivo mouse tibial loading model using microCT-based finite element analysis. Bone 2014;66:131-9.

164. Webster D, Müller R. In silico models of bone remodeling from macro to nano- from organ to cell. Wiley Interdilscip Rev Syst Biol Med 2011;3:241-51.

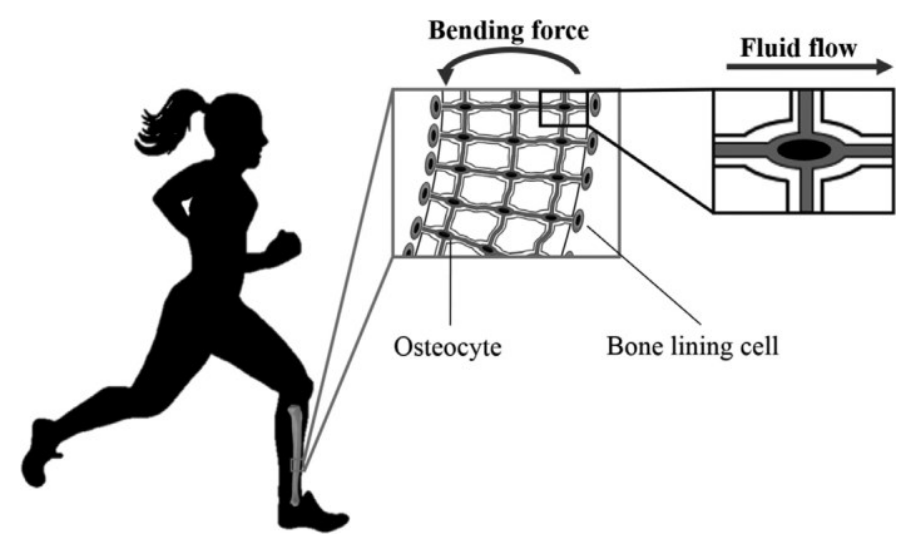

Fig. 1. Schematic representation of mechanical loading that causes interstitial fluid flow through bone's lacuna-canalicular network (adapted from Duncan et al. [9]). The tension/compression stresses associated with bending cause a pressure gradient that promotes fluid flow along the osteocytes.

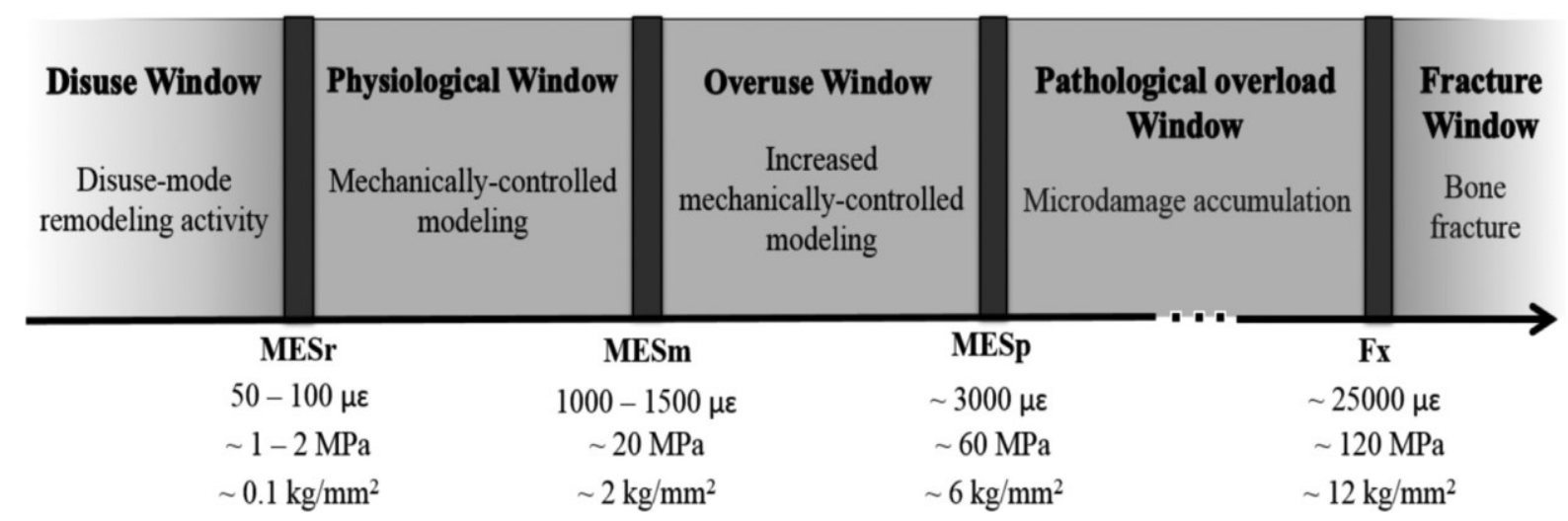

Fig. 2. Mechanical usage window defined by Frost's "mechanostat" theory of bone adaptation to strain (adapted from Duncan et al. [9] and Frost [95]). The 
horizontal arrow at the bottom shows the typical minimum effective strain (MES) levels and the set point values for bone's thresholds and ultimate strength - microstrain $(\mu \varepsilon)$, stress (MPa) and unit-load $\left(\mathrm{kg} / \mathrm{mm}^{2}\right)$.

\section{Table 1}

In vivo humans bone strain values measured during different types of physical activities, reported in the literature

\begin{tabular}{|c|c|c|c|c|c|c|c|c|}
\hline \multirow[t]{2}{*}{ Activity } & \multirow[t]{2}{*}{ Type } & \multicolumn{2}{|l|}{ Strain $(\mu \varepsilon)$} & \multicolumn{2}{|c|}{ Strain rate $\left(\mu_{\varepsilon} / \mathrm{sec}\right)$} & \multirow[t]{2}{*}{ Region ${ }^{\mathrm{a}}$} & \multirow[t]{2}{*}{ Test $^{\mathrm{b}}$} & \multirow[t]{2}{*}{ References } \\
\hline & & Compressive & Tensile & Compressive & Tensile & & & \\
\hline \multirow[t]{7}{*}{ Walking } & Level & 308 & - & 2300 & - & (A) & (a) & [92] \\
\hline & & 544 & 437 & 7183 & 11006 & - & & [96] \\
\hline & & 334 & - & - & - & (B) & (b) & [97] \\
\hline & & 950 & - & - & - & (C) & & \\
\hline & & 454 & 840 & 3306 & 3955 & (D) & (c) & [106] \\
\hline & Uphill & 630 & 440 & 8176 & 7113 & - & (a) & [96] \\
\hline & Downhill & 414 & 531 & 10846 & 9566 & - & & \\
\hline \multirow[t]{3}{*}{ Walking ( $\geq 20 \mathrm{~kg}$ ) } & Level & 557 & 381 & 6437 & 11434 & - & & \\
\hline & Uphill & 680 & 509 & 10645 & 8989 & - & & \\
\hline & Downhill & 751 & 601 & 17892 & 9839 & - & & \\
\hline Walking (21-45 kg) & Level & 393 & - & $2500-2700$ & - & (A) & & [92] \\
\hline Walking ( $\leq 46 \mathrm{~kg})$ & Level & 412 & - & - & 4200 & & & \\
\hline \multirow[t]{5}{*}{ Running } & Jogging & 879 & 625 & 27376 & 13913 & - & & [96] \\
\hline & Sprint $(13.88 \mathrm{~km} / \mathrm{h})$ & 1321 & 646 & 34457 & 20237 & - & & \\
\hline & Sprint $(17 \mathrm{~km} / \mathrm{h})$ & 2104 & 1415 & 14543 & 7780 & (D) & (c) & [98] \\
\hline & Uphill & 954 & 633 & 23834 & 17475 & - & (a) & [96] \\
\hline & Downhill & 517 & 707 & 26337 & 16710 & - & & \\
\hline \multirow[t]{2}{*}{ Zigzag running } & Uphill & 1226 & 743 & 20930 & 13638 & - & & \\
\hline & Downhill & 1147 & 707 & 30039 & 15653 & - & & \\
\hline Bicycle & 60 cycles/s & 291 & 271 & 1510 & 1286 & (D) & - & [106] \\
\hline \multirow[t]{2}{*}{ Forward jump } & $30 \mathrm{~cm}$ & 1600 & - & - & - & (B) & (b) & [97] \\
\hline & & 3450 & - & - & - & (C) & & \\
\hline \multirow[t]{5}{*}{ Vertical drop } & Height of $26 \mathrm{~cm}$ & 1905 & 896 & 13178 & 7621 & (D) & (c) & [98] \\
\hline & Height of $39 \mathrm{~cm}$ & 1990 & 921 & 11342 & 5021 & & & \\
\hline & Height of $45 \mathrm{~cm}$ & 2128 & - & - & - & (B) & (b) & [97] \\
\hline & & 436 & - & - & - & (C) & & \\
\hline & Height of $52 \mathrm{~cm}$ & 2098 & 1007 & 8663 & 4796 & (D) & (c) & [98] \\
\hline
\end{tabular}

a The anatomical regions considered in these articles were: (A) Anteromedial aspect of the tibial midshaft, (B) Anterior middiaphysis of the distal tibia, (C) Posteromedial part of the distal tibia and (D) Medial aspect of the mid-diaphysis of the tibia.

b The subjects used in the studies were all active healthy adult: (a) male. (b) female and (c) males and female group tests. 